\title{
Clinical Impact of Delayed Initiation of Adjuvant Chemotherapy among Patients with Stage II/III Gastric Cancer: Can We Do Better?
}

\section{Qiyue Chen}

Fujian Medical University Union Hospital

Zhiyu Liu

Fujian Medical University Union Hospital

Qing Zhong

Fujian Medical University Union Hospital

Jianwei Xie

FMUUH

Jiabin Wang

FMUUH

Jianxian Lin

FMUUH

Jun Lu

FMUUH

Longlong Cao

FMUUH

Mi Lin

FMUUH

Ruhong Tu

FMUUH

Zening Huang

FMUUH

Juli Lin

FMUUH

Hualong Zheng

FMUUH

Ping Li

FMUUH

Chaohui Zheng

FMUUH

Chang-ming Huang ( $\nabla$ hcmlr2002@163.com ) 
Fujian Medical University Union Hospital https://orcid.org/0000-0002-0019-885X

\section{Research article}

Keywords: gastric carcinoma, prognosis, untimely, chemotherapy, risk factor

Posted Date: August 15th, 2019

DOI: https://doi.org/10.21203/rs.2.12979/v1

License: (c) (i) This work is licensed under a Creative Commons Attribution 4.0 International License. Read Full License

Version of Record: A version of this preprint was published at Frontiers in Oncology on July 31st, 2020. See the published version at https://doi.org/10.3389/fonc.2020.01149. 


\section{Abstract}

BACKGROUNDS To investigate the prognostic effects and risk factors of the omission and delay of postoperative chemotherapy of stage II/III gastric cancer (GC). METHODS The clinicopathological data of 1520 patients undergoing radical gastrectomy for stage II/III GC were collected and retrospectively analyzed. We defined the chemotherapy delayed until more than 60 days after radical gastrectomy and the complete omission of chemotherapy as unacceptable chemotherapy initiation (UAC group), while the chemotherapy conducted within 60 days of radical gastrectomy was defined as acceptable chemotherapy initiation (AC group). The survival between the two groups was compared, and the trends and risk factors of UAC were analyzed. RESULTS There were 539 (35.5\%) patients with UAC. The OS and DFS of the UAC group patients were significantly inferior to those in the AC group $(p<0.001)$. Cox multivariate analysis demonstrated that UAC is an independent predictor of OS $(p<0.05)$. The OS and DFS of the patients in UAC group were close to those of the patients without chemotherapy $(p>0.05)$. Logistic analysis showed female, old age, a self-paid status, a very low social status, high ASA scores, intraabdominal surgery history, and serious postoperative complications were independent risk factors of UAC $(p<0.05)$. The radar chart shows the risk factors of UAC changed with time. CONCLUSIONS UAC after radical gastrectomy is an independent risk factor for the prognosis of stage II/III GC patients. However, no significant decline of UAC has been achieved recently and should call for the attention of both government and clinicians.

\section{Introduction}

Although the incidence of gastric cancer (GC) has declined in recent years, its mortality rate remains at the forefront of cancer-related deaths $(1-3)$. Scholars have spent great effort to explore how to improve the survival rate of GC, particularly in advanced stage patients, including the constant perfection of surgical methods and the continuous improvement of chemotherapy regimens(4-10); however, the effect is still not ideal. Therefore, it may not be enough to rely solely on clinicians to improve the overall survival rate of GC. The concerted efforts of the government, the family and the patients should be employed. In particular, for the majority of Chinese patients with locally advanced GC (Stage II/III) (11), the regulation of $\mathrm{D} 2$ radical surgery may only be the beginning of treatment. Whether adjuvant chemotherapy can be performed in time may also determine the overall effect of treatment. We observed in clinical practice that some patients with delayed chemotherapy had a significantly poorer prognosis compared with those with timely chemotherapy. The delay or omission of chemotherapy may occur for various reasons in patients with GC, particularly in developing countries, such as China. It is critical for clinical workers and health departments to determine its precise effect on prognosis and how to detect high-risk patients as early as possible. However, to our knowledge, there are no accurate data for the omission and delay of chemotherapy in GC, and there is a lack of relevant research on its effect on the prognosis of GC patients. Closure of this knowledge gap is critical for researchers, surgeons, and administrators. Clearly, it is unfeasible and unethical to explore this issue through prospective trials. Therefore, this paper aims to investigate the effects of the omission and delay of chemotherapy in stage II/III GC and its risk factors in 
recent years from a large tertiary referral center in southern China; moreover, the goals are to assess the effect on prognosis and identify the high-risk factors of delayed chemotherapy and the trends in recent years to provide a reference for the intervention of relevant departments, including the government and clinicians.

\section{Methods And Materials}

\section{Study design and patients}

In this study, the clinical and pathological data of 2604 patients with gastric cancer at the Fujian Medical University Union Hospital(FMUUH) from January 2011 to April 2015 were retrospectively analyzed, and the case exclusion criteria were as follows: (1) The postoperative pathology was confirmed as stage I or IV gastric cancer ( $n=1025$ cases); (2) Histological identification of a tumor type other than adenocarcinoma ( $n=13$ cases); (3) Remnant gastric cancer ( $n=23$ cases); and (4) Survival time is less than 3 months ( $n=23$ cases). Finally, 1520 patients with stage II/III gastric adenocarcinoma treated with D2 radical resection were included. Supplementary Fig. 1 shows the screening process. This study was conducted with the approval of the institutional review boards at FMUUH. The time of chemotherapy was defined as the interval between the radical gastrectomy and the first initiation time of chemotherapy. According to the correlation between the overall survival (OS) rate and the chemotherapy time, the cutoff value of the chemotherapy time was selected (supplementary Fig. 2). The results showed that the OS of the patients treated with chemotherapy within less than 4 weeks, 4-6 weeks and 6-8 weeks were significantly better than those who had no chemotherapy $(p<0.05)$, while the OS of the patients treated with chemotherapy after 8-10 weeks, 10-12 weeks and more than 12 weeks were similar to those without chemotherapy ( $p>0.05$ ). To facilitate the analysis, we selected the cutoff point with the duration of chemotherapy over 60 days as the delay of chemotherapy.

Accordingly, we defined chemotherapy that was delayed until more than 60 days after radical gastrectomy and the complete omission of chemotherapy as unacceptable chemotherapy initiation (UAC group), while chemotherapy conducted within 60 days of radical gastrectomy was defined as acceptable chemotherapy initiation (the AC group). The chemotherapy regimen does not change for each patient unless there is a severe chemotherapy reaction. This retrospective study was approved and implemented by the Ethics committee of Fujian Medical University Union hospital.

\section{Methods}

Preoperative imaging studies were routinely performed following endoscopic and upper gastrointestinal examinations with contrast to confirm the tumor location and included chest radiography, computed tomography (CT) scanning, ultrasonography (US) of the abdomen and bone scanning and positron emission tomography-computed tomography (PET-CT) as required to evaluate the clinical stage. We used CT scans and the 7th edition of the International Union Against Cancer (UICC) classification system to assess the clinical and pathologic stage(12). According to the 2014 version of the Japanese Gastric 
Cancer treatment guidelines(13), our center recommended 5-fu-based chemotherapy for patients with postoperative pathological stage II/III. The patient's residential address, marital status, procreation status, type of medical insurance, occupation, smoking history, alcohol consumption and other information were routinely recorded in the electronic database of the Fujian Medical University union Hospital medical records. The financial condition of the patient was recorded by the health care system. We conducted a comprehensive assessment of the patient's social status based on the patient's occupation, residential address, education, and economic conditions according to literature(14).

\section{Follow up}

The last follow-up time was April 2018. The follow-up rate of the 1520 patients was $95.9 \%$. Postoperative follow-up using outpatient, hospitalization, etc., every 3 months for the first 2 years, every 6 months for 3-5 years and every year for after 5 years. The overwhelming majority of the patients routinely received physical examinations, laboratory tests (including CA19-9, ca72-4, and CEA levels), chest films, full belly color Doppler ultrasound or abdominal CT, and an annual gastroscopy. The OS time represents the time from the operation to the last follow-up or death. Disease-free survival (DFS) was defined as the time from the surgery to the time of recurrence or death from any other cause.

\section{Statistical analysis}

All data were processed using SPSS 20.0 (SPSS Inc., Chicago, IL). Continuous variables were analyzed with Student's $t$ tests, and categorical variables were analyzed with $\chi 2$ or Fisher's tests. The survival rate was calculated using the Kaplan-Meier method, and the survival rates were compared with the Log-rank test. The risk factors related to UAC were analyzed using a logistic model, with a Cox proportional risk model for multivariate prognostic analysis. Stepwise backward variable removal was applied to the multivariate model to identify the most accurate and parsimonious set of predictors. A p-value less than 0.05 was considered statistically significant.

\section{Results}

\section{Patient characteristics between UAC and AC groups}

Of all patients, there were 539 patients with UAC, with an incidence of $35.5 \%$. Table 1 shows the clinicopathologic data of the patients in the AC and UAC groups. There were significant differences in terms of age, gender, medical insurance type, income, social status, residential address, ASA score, intraabdominal surgery history, comorbidities, Charlson score, surgery period, and postoperative complications between the two groups $(\mathrm{p}<0.05)$; however, the $\mathrm{BMI}$, occupation, marital status, procreation status, smoking and drinking consumption, abdominal surgery history, tumor site, pT stage, pN stage, pTNM staging, tumor size, number of harvested lymph nodes, lymphatic vessel infiltration and pathological differentiation degree were not significantly different between the groups $(p>0.05)$. The 
median follow-up times for the AC and UAC groups were 43 (3-86) months and 37 (3-91) months, respectively. The analysis of the UAC status from 2011 to April 2015 showed that the rates in 2011, 2012, 2013, 2014 and 2015 were 53.2\%, 31.7\%, 29.7\%, 29.1\% and 30.7\%, respectively (Fig. 1). The difference reached statistical significance $(P<0.001)$. A further stratified analysis showed a significant improvement in UAC in 2012 compared to that in 2011 ( $p<0.001)$, while there was no significant improvement during 2012-2015 April $(p=0.880)$; moreover, it increased from 29.1 percent in 2014 to 30.7 percent in 2015 .

\section{The effect of UAC on prognosis}

Supplementary Fig. 3 shows the OS of the 1520 patients, with a median survival time of 41 months (range 3-91 months). Fig. 2 indicates that the OS and DFS of the UAC group patients are significantly inferior to those in the AC group ( $p<0.001)$. In the UAC group, the OS and DFS of the patients with chemotherapy delayed until more than 60 days were close to those without chemotherapy $(p>0.05)$. Further analysis shows that the AC group had significantly better OS than the UAC group $(p<0.05)$ in both men/women, with or without complications, or stage II/III (supplementary Fig. 4).

The stratified analysis by stage II/III shows that the OS in the AC Group in the IIA-IIIC patients was significantly better than in the UAC group $(P<0.05)$. When the DFS was compared, the AC group was significantly superior to the UAC group in both males and females, with or without complications, or stage II/III patients $(P<0.05)$ (Supplementary Fig. 5). A further stratified analysis by stage II/III demonstrates that the DFS in the AC Group exhibited a greater trend than that in the UAC group in the IIb, IIIA and IIIC patients; however, the differences were not significant ( $p>0.05)$. In contrast, in the AC group in the IIA

and IIIB patients, the DFS was significantly better than that in the UAC group $(p<0.05)$.

\section{Analysis of risk factors for patient survival}

Table 2 shows the results of the Cox univariate and multivariate analyses for OS. The univariate analysis indicates that age, BMI, medical insurance type, ASA score, comorbidities, tumor site, pTNM staging, tumor size, lymphatic vessel infiltration, pathological differentiation degree, number of examined lymph nodes, Clavien-Dindo grade, and UAC were associated with OS (all $p<0.05)$. The multivariate analysis indicates that age, BMI, ASA Score, comorbidities, pTNM staging, number of examined lymph nodes, Clavien-Dindo grade, and UAC were independent predictors of OS $(P-0.05)$. Supplementary Table 1 demonstrates that age, pTNM staging, tumor size and number of harvested lymph nodes were independent predictors of DFS; however, UAC was not an independent risk factor $(p<0.05)$.

\section{Analysis of risk factors of UAC}

Table 3 presents the results of the logistic univariate and multivariate analyses of risk factors associated with UAC. The univariate analysis shows that gender, age, type of medical insurance, income, social 
status, residential address, ASA score, history of intra-abdominal surgery, Charlson score and ClavienDindo grade were related to UAC (all $p<0.05$ ). The reduced multivariate model analysis shows that female sex, old age, self-paid status, very low social status, high ASA score, intra-abdominal surgery history, and postoperative serious complications (Clavien-Dindo III-IV) were independent risk factors for $\operatorname{UAC}(\mathrm{p}<0.05)$.

\section{The change of risk factors for UAC over time}

The radar chart shows that the risk factors of UAC changed with time (Fig. 3). In general, the number of patients with self-funded and an extremely low social status significantly decreased from 2011 to April 2015 (all $p<0.05$ ). The proportion of self-funded patients showed a downward trend year by year from 2011 to April 2015, while the proportion of extremely low social status patients gradually decreased (0 3.2\%) from 2011 to 2014 and then increased again (4.5\%) in 2015 (Supplement Table 2). Between 2011 and April 2015, there was no significant change in the proportion of female patients, aged patients, patients undergoing intra-abdominal surgery, and high ASA patients (all $p>0.05$ ). At the same time, the proportion of patients with severe postoperative complications was not significantly improved $(p=$ $0.549)$.

\section{Discussion}

It has been confirmed in animal models that the angiogenesis of the micrometastatic foci will be significantly faster after resection of the primary cancer(15-17); thus, the treatment of advanced cancer cannot rely solely on surgical treatment(18-21). Therefore, although surgery is a key part of the comprehensive treatment for local advanced GC, timely adjuvant chemotherapy plays an important role. Our results show that the patients with a chemotherapy delay (delayed more than 60 days) or without chemotherapy have significantly worse overall and disease-free survival than those with timely chemotherapy. The patients with delayed or omitted chemotherapy did not exhibit significant differences, and the chemotherapy delay patients' sample size was limited. Thus, we combined them in the subsequent analysis as UAC. Our data show that UAC is a risk factor for OS independent of tumor staging, age and other factors for STAGE II/III stage GC patients. The reason may be that a chemotherapy delay can affect the early inhibition of cytotoxic drugs on angiogenesis in micrometastasis, and it is easy to induce primary drug resistance $(17,22)$. UAC is not an independent risk factor for the survival of all patients with STAGE II/III GC, and the reasons require further discussion.

As an independent risk factor for OS, clinicians should avoid the occurrence of UAC in patients. The rate of UAC in recent years was significantly reduced from 2011 to 2012; however, the rate did not significantly decrease from 2012 to 2015 and increased from $29.1 \%$ in 2014 to $30.7 \%$ in 2015 . Therefore, it is of importance to identify the high-risk factors of UAC and investigate their changes overtime to facilitate relevant departments to employ appropriate measures to improve this situation. At the same time, we believe that the causes of UAC are not only related to clinical treatment factors, such as surgery, 
postoperative complications and tumor factors, and individual factors, such as socioeconomic variables, may also play important roles. Therefore, we expanded the included variables, such as the medical insurance type, according to the characteristics of the regional socioeconomic factors and divided the included factors into three categories, including individual, treatment and tumor, for logistic analysis. The results showed that female, elderly, self-paid patients and patients with a low social status, high ASA score, preoperative abdominal operation history and severe postoperative complications exhibited high risk factors of UAC, while tumor factors, such as tumor size and staging, did not affect postoperative chemotherapy time. Further analysis indicated the risk factors change over time in the intervening factors with the increase in time, the surgical experience accumulated, while serious postoperative complications did not significantly improve. Severe postoperative complications often require longer recovery times and may affect patients' confidence in themselves and their doctors' treatment(23), thus delaying their first time of receiving chemotherapy. Moreover, low-status groups typically suffer from substantial life pressures; thus, they often delay or give up chemotherapy due to personal or family factors after surgery. Therefore, although through the unremitting efforts of the government, the proportion of self-financed patients decreases year by year (which can improve the patient's willingness and timeliness of chemotherapy), the rate of UAC has not significantly improved in recent years.

We believe that to improve the OS of gastric cancer, the relevant departments or personnel should take corresponding measures in response to the various factors that cause UAC. For clinical workers, preoperative evaluation, intraoperative quality control and enhanced postoperative management should be performed to reduce postoperative complications, particularly severe postoperative complications. At the same time, postoperative care and education should receive attention in high-risk groups, such as individuals with a low social status, to inform them of the importance of timely postoperative chemotherapy. The government should continue to improve the medical insurance policy to continue to reduce the proportion of self-funded patients.

This paper is the first study of the effect of postoperative UAC on the prognosis of patients with gastric cancer. It incorporates multiple factors to explore high-risk groups to provide a reference for relevant departments and personnel to employ corresponding measures. However, our research has unavoidable shortcomings: First, as a retrospective study, it is difficult to exclude the effects of confounding factors on the results, i.e., the patient's personal preferences may have an impact on the UAC; Second, some patients, such as those with a very low social status, are limited in number at the time of stratification, which may affect the results; Third, the risk factors for UAC in different countries may vary due to different national conditions, such as health care policies and income conditions $(24,25)$. Nevertheless, the results of this retrospective study are important because it is difficult to conduct prospective studies due to ethical concerns. We also look forward to the international, multicenter, retrospective study in the near future to explore the risk factors and their differences in each country, thus providing strategies for improving the overall prognosis of patients with gastric cancer worldwide.

\section{List Of Abbreviations}


unacceptable chemotherapy initiation (UAC group);

acceptable chemotherapy initiation (AC group);

unacceptable chemotherapy initiation (UAC group);

acceptable chemotherapy initiation (AC group);

gastric cancer (GC);

Fujian Medical University Union Hospital(FMUUH);

computed tomography (CT);

ultrasonography (US);

positron emission tomography-computed tomography (PET-CT);

the International Union Against Cancer (UICC);

Disease-free survival (DFS);

\section{Declarations}

\section{Ethics approval and consent to participate:}

The research proposal was reviewed by the Research Ethics Committee at the Fujian Medical University Union Hospital (the reference number is N0.2019KY063), and all procedures were performed after obtaining written informed consent from the patients following an explanation of the surgical and oncological risks.

\section{Consent for publication}

All the authors agree to the publication of this article

\section{Competing interests:}

All authors declare no conflicts-of-interest related to this article.

\section{Availability of data and material:}

We declare that all the data of this article are availability. 


\section{Funding:}

Scientific and technological innovation joint capital projects of Fujian Province (2016Y9031), Construction Project of Fujian Province Minimally Invasive Medical Center囚No. [2017]171囚, The second batch of special support funds for Fujian Province innovation and entrepreneurship talents (2016B013),General project of Miaopu scientific research fund of Fujian Medical University (2015MP021), Youth Project of Fujian Provincial Health and Family Planning Commission『2016-1-41区, Nature Fund Health Joint Fund Project of Fujian Province(2015J01464)

\section{Author contributions:}

Conception/Design: Chen QY, Liu ZY, Zhong Q, and Huang CM; Provision of study materials or patients: Huang CM; Collection and/or assembly of data: Chen QY, Liu ZY, Zhong Q, Huang CM, Li P, Zheng CH, Lin JX, Xie JW, Wang JB, Lu J, Cao LL, Lin JL and Tu RH; Data analysis and interpretation: Huang CM, Chen QY, Liu ZY Zhong Q and Huang ZN; Manuscript writing: Huang CM, Li P, Chen QY, Zhong Q Lin M and Zheng HL;

All authors read and approved the final manuscript.

\section{Informed consent statement:}

Patients were not required to give informed consent to the study because the analysis used anonymous clinical data that were obtained after each patient agreed to treatment by written consent.

\section{References}

1.Bray F, Ferlay J, Soerjomataram I, Siegel RL, Torre LA, Jemal A. Global cancer statistics 2018: GLOBOCAN estimates of incidence and mortality worldwide for 36 cancers in 185 countries. CA Cancer J Clin. 2018;68(6):394-424.

2.Zeng H, Chen W, Zheng R, Zhang S, Ji JS, Zou X, et al. Changing cancer survival in China during 200315: a pooled analysis of 17 population-based cancer registries. Lancet Glob Health. 2018;6(5):e555-e67.

3.Allemani C, Matsuda T, Di Carlo V, Harewood R, Matz M, Niksic M, et al. Global surveillance of trends in cancer survival 2000-14 (CONCORD-3): analysis of individual records for 37513025 patients diagnosed with one of 18 cancers from 322 population-based registries in 71 countries. Lancet. 2018;391(10125):1023-75.

4.Bang YJ, Xu RH, Chin K, Lee KW, Park SH, Rha SY, et al. Olaparib in combination with paclitaxel in patients with advanced gastric cancer who have progressed following first-line therapy (GOLD): a doubleblind, randomised, placebo-controlled, phase 3 trial. Lancet Oncol. 2017;18(12):1637-51. 
5. Hu Y, Huang C, Sun Y, Su X, Cao H, Hu J, et al. Morbidity and Mortality of Laparoscopic Versus Open D2 Distal Gastrectomy for Advanced Gastric Cancer: A Randomized Controlled Trial. J Clin Oncol. 2016;34(12):1350-7.

6. Ishigami H, Fujiwara Y, Fukushima R, Nashimoto A, Yabusaki H, Imano M, et al. Phase III Trial Comparing Intraperitoneal and Intravenous Paclitaxel Plus S-1 Versus Cisplatin Plus S-1 in Patients With Gastric Cancer With Peritoneal Metastasis: PHOENIX-GC Trial. J Clin Oncol. 2018;36(19):1922-9.

7.Kinoshita T, Uyama I, Terashima M, Noshiro H, Nagai E, Obama K, et al. Long-term Outcomes of Laparoscopic Versus Open Surgery for Clinical Stage II/III Gastric Cancer: A Multicenter Cohort Study in Japan (LOC-A Study). Ann Surg. 2019;269(5):887-94.

8. Shitara K, Ozguroglu M, Bang YJ, Di Bartolomeo M, Mandala M, Ryu MH, et al. Pembrolizumab versus paclitaxel for previously treated, advanced gastric or gastro-oesophageal junction cancer (KEYNOTE061): a randomised, open-label, controlled, phase 3 trial. Lancet. 2018;392(10142):123-33.

9.So JB, Rao J, Wong AS, Chan YH, Pang NQ, Tay AYL, et al. Roux-en-Y or Billroth II Reconstruction After Radical Distal Gastrectomy for Gastric Cancer: A Multicenter Randomized Controlled Trial. Ann Surg. 2018;267(2):236-42.

10. Tabernero J, Hoff PM, Shen L, Ohtsu A, Shah MA, Cheng K, et al. Pertuzumab plus trastuzumab and chemotherapy for HER2-positive metastatic gastric or gastro-oesophageal junction cancer (JACOB): final analysis of a double-blind, randomised, placebo-controlled phase 3 study. Lancet Oncol. 2018;19(10):1372-84.

11. Chen W, Zheng R, Baade PD, Zhang S, Zeng H, Bray F, et al. Cancer statistics in China, 2015. CA Cancer J Clin. 2016;66(2):115-32.

12.Edge SB, Compton CC. The American Joint Committee on Cancer: the 7th edition of the AJCC cancer staging manual and the future of TNM. Ann Surg Oncol. 2010;17(6):1471-4.

13. Japanese Gastric Cancer A. Japanese gastric cancer treatment guidelines 2014 (ver. 4). Gastric Cancer. 2017;20(1):1-19.

14. Yost $K$, Perkins $\mathrm{C}$, Cohen $\mathrm{R}$, Morris $\mathrm{C}$, Wright W. Socioeconomic status and breast cancer incidence in California for different race/ethnic groups. Cancer Causes Control. 2001;12(8):703-11.

15.Fisher B, Gunduz N, Coyle J, Rudock C, Saffer E. Presence of a growth-stimulating factor in serum following primary tumor removal in mice. Cancer Res. 1989;49(8):1996-2001.

16. Folkman J. Endothelial cells and angiogenic growth factors in cancer growth and metastasis. Introduction. Cancer Metastasis Rev. 1990;9(3):171-4. 
17. Gunduz N, Fisher B, Saffer EA. Effect of surgical removal on the growth and kinetics of residual tumor. Cancer Res. 1979;39(10):3861-5.

18.Gambardella $V$, Cervantes A. Precision medicine in the adjuvant treatment of gastric cancer. Lancet Oncol. 2018;19(5):583-4.

19.Ge S, Xia X, Ding C, Zhen B, Zhou Q, Feng J, et al. A proteomic landscape of diffuse-type gastric cancer. Nat Commun. 2018;9(1):1012.

20. Van Cutsem E, Sagaert X, Topal B, Haustermans K, Prenen H. Gastric cancer. Lancet. 2016;388(10060):2654-64.

21.Wang J, Li C, Zhu X, Zhu J. Adjuvant therapy in resectable gastric cancer-the CRITICS trial. Lancet Oncol. 2018;19(7):e330.

22. Goldie JH, Coldman AJ. A mathematic model for relating the drug sensitivity of tumors to their spontaneous mutation rate. Cancer Treat Rep. 1979;63(11-12):1727-33.

23.Sprenger T, Beissbarth T, Sauer R, Tschmelitsch J, Fietkau R, Liersch T, et al. Long-term prognostic impact of surgical complications in the German Rectal Cancer Trial CAO/ARO/AIO-94. Br J Surg. 2018;105(11):1510-8.

24.Adler-Milstein J, Sarma N, Woskie LR, Jha AK. A comparison of how four countries use health IT to support care for people with chronic conditions. Health Aff (Millwood). 2014;33(9):1559-66.

25.Dare AJ, Bleicher J, Lee KC, Elobu AE, Kamara TB, Liko O, et al. Generation of national political priority for surgery: a qualitative case study of three low-income and middle-income countries. Lancet. 2015;385 Suppl 2:S54.

\section{Tables}

Table 1. Sociodemographic and clinicopathologic variables of the AC and UAC groups 


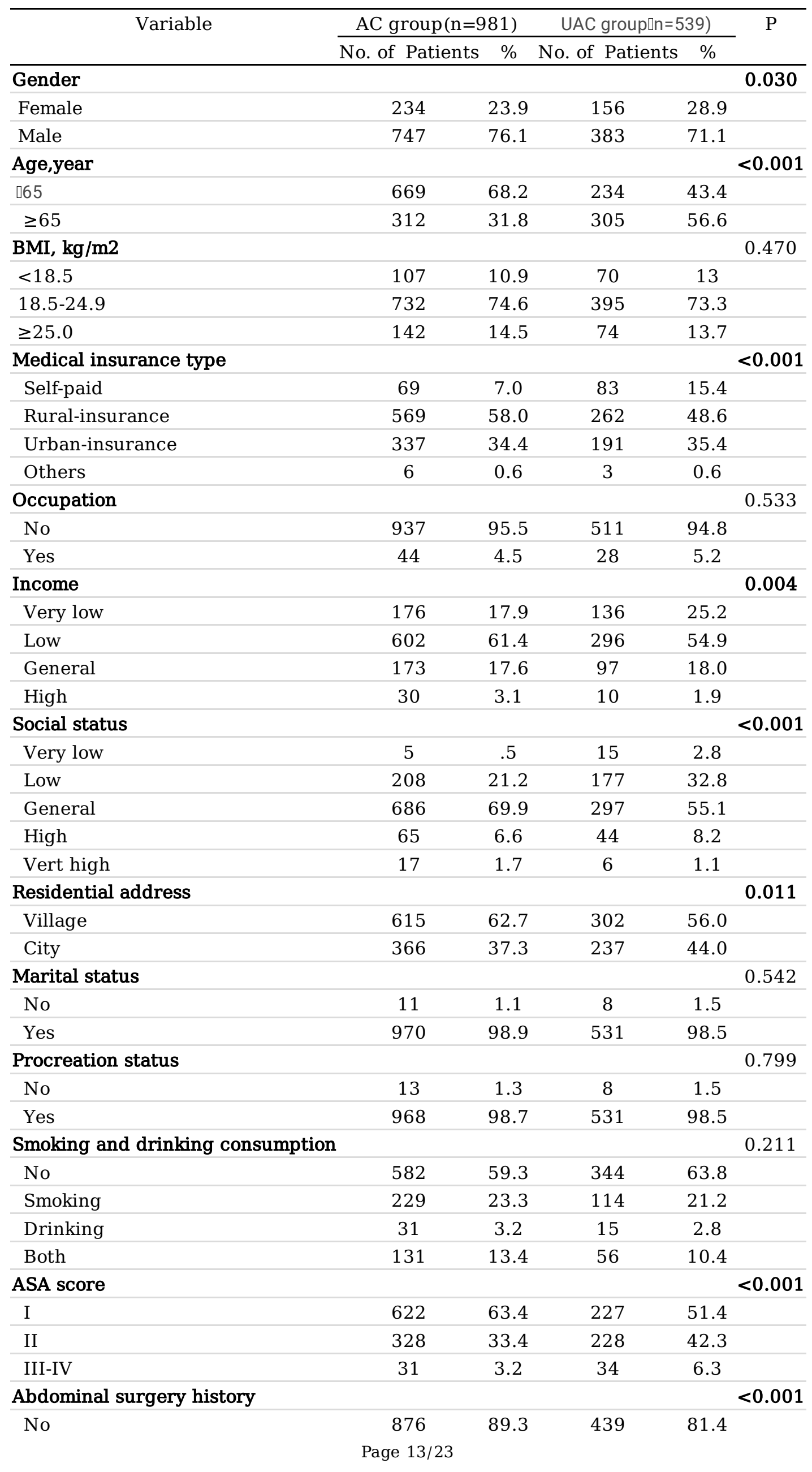




\begin{tabular}{|c|c|c|c|c|c|}
\hline Yes & 105 & 10.7 & 100 & 18.6 & \\
\hline Intra-abdominal surgery history & & & & & 0.500 \\
\hline No & 912 & 93.0 & 496 & 92.0 & \\
\hline Yes & 69 & 7.0 & 43 & 8.0 & \\
\hline Comorbidity & & & & & $<0.001$ \\
\hline No & 730 & 74.4 & 345 & 64.0 & \\
\hline Yes & 251 & 25.6 & 194 & 36.0 & \\
\hline Charlson score & & & & & $<0.001$ \\
\hline 0 & 730 & 74.4 & 345 & 64.0 & \\
\hline $1-2$ & 236 & 24.1 & 187 & 34.7 & \\
\hline $3-5$ & 15 & 1.5 & 7 & 1.3 & \\
\hline Tumor site & & & & & 0.684 \\
\hline Lower & 352 & 35.9 & 194 & 36.0 & \\
\hline Middle & 223 & 22.7 & 109 & 20.2 & \\
\hline Upper & 272 & 27.7 & 157 & 29.1 & \\
\hline Overlapping lesion of stomach & 134 & 13.7 & 79 & 14.7 & \\
\hline Surgery period & & & & & $<0.001$ \\
\hline 2011 & 162 & 16.50 & 184 & 34.10 & \\
\hline 2012 & 263 & 26.80 & 122 & 22.60 & \\
\hline 2013 & 241 & 24.60 & 102 & 18.90 & \\
\hline 2014 & 254 & 25.90 & 104 & 19.30 & \\
\hline 2015 & 61 & 6.20 & 27 & 5.00 & \\
\hline Depth of invasion(pT) & & & & & 0.296 \\
\hline Mucosa/Submucosa & 24 & 2.4 & 9 & 1.7 & \\
\hline Proper muscle & 82 & 8.4 & 33 & 6.1 & \\
\hline Subserosa & 421 & 42.9 & 243 & 45.1 & \\
\hline Serosa & 454 & 46.3 & 254 & 47.1 & \\
\hline Nodal status(pN) & & & & & 0.284 \\
\hline No & 140 & 14.3 & 92 & 17.1 & \\
\hline N1 & 176 & 17.9 & 82 & 15.2 & \\
\hline N2 & 246 & 25.1 & 127 & 23.6 & \\
\hline N3 & 419 & 42.7 & 238 & 44.2 & \\
\hline pTNM stage & & & & & 0.222 \\
\hline IIA & 153 & 15.6 & 90 & 16.7 & \\
\hline IIB & 159 & 16.2 & 80 & 14.8 & \\
\hline IIIA & 171 & 17.4 & 72 & 13.4 & \\
\hline IIIB & 234 & 23.9 & 144 & 26.7 & \\
\hline IIIC & 264 & 26.9 & 153 & 28.4 & \\
\hline Tumor size, mm & & & & & 0.105 \\
\hline$<20$ & 31 & 3.2 & 17 & 3.2 & \\
\hline $20-50$ & 546 & 55.7 & 270 & 50.1 & \\
\hline$>50$ & 404 & 41.2 & 252 & 46.8 & \\
\hline Examined LNs, No. & & & & & 0.629 \\
\hline$\leq 15$ & 25 & 2.5 & 16 & 3.0 & \\
\hline$>15$ & 956 & 97.5 & 523 & 97.0 & \\
\hline Lymphatic vessel infiltration & & & & & 0.326 \\
\hline Negative & 502 & 51.2 & 290 & 53.8 & \\
\hline Positive & 479 & 48.8 & 249 & 46.2 & \\
\hline Postoperative complications & & & & & 0.001 \\
\hline No & 823 & 83.9 & 413 & 76.6 & \\
\hline
\end{tabular}




\begin{tabular}{|c|c|c|c|c|}
\hline Yes & 158 & 16.1 & 126 & 23.4 \\
\hline Clavien-Dindo grade & & & & $<0.001$ \\
\hline None & 823 & 83.9 & 413 & 76.6 \\
\hline I-II & 133 & 13.6 & 76 & 14.1 \\
\hline III-IV & 25 & 2.5 & 50 & 9.3 \\
\hline \multicolumn{5}{|l|}{ Chemotherapy } \\
\hline AC group & 981 & 100 & 0 & 0.0 \\
\hline UAC group & 0 & 0 & 539 & 100.0 \\
\hline Delay(>60 days) & 0 & 0 & 62 & 11.5 \\
\hline Omission & 0 & 0 & 477 & 88.5 \\
\hline Pathological differentiation degree & & & & 0.342 \\
\hline Differentiated & 753 & 76.8 & 402 & 74.6 \\
\hline Undifferentiated & 228 & 23.2 & 137 & 25.4 \\
\hline \multicolumn{5}{|l|}{ Follow-up, month } \\
\hline Median & 43 & & 37 & \\
\hline Range & $3-86$ & & $3-91$ & \\
\hline
\end{tabular}

AC: Acceptable chemotherapy, UAC: Unacceptable delay or missing chemotherapy

Table 2. Univariate and multivariate cox regression models for overall survival 


\begin{tabular}{|c|c|c|c|c|c|c|c|c|}
\hline \multirow{2}{*}{\multicolumn{2}{|c|}{ Variable }} & \multicolumn{2}{|c|}{ Univariate Model } & \multicolumn{2}{|c|}{$\begin{array}{c}\text { Full Multivariate } \\
\text { Model }\end{array}$} & \multicolumn{3}{|c|}{$\begin{array}{c}\text { Reduced Multivariate } \\
\text { Model }\end{array}$} \\
\hline & & HR $95 \% C I$ & $\mathrm{P}$ & HR $\quad 95 \% C I$ & $\mathrm{P}$ & HR & $95 \%$ CI & $\mathrm{P}$ \\
\hline \multirow[t]{42}{*}{ Patients' risk } & Gender & & 0.565 & & & & & \\
\hline & Female & Ref & & & & & & \\
\hline & Male & 1.050 .891 .25 & 0.565 & & & & & \\
\hline & Age,year & & 0.002 & & 0.003 & & & 0.003 \\
\hline & $<65$ & Ref & & Ref & & Ref & & \\
\hline & $\geq 65$ & 1.271 .091 .48 & 0.002 & 1.291 .091 .53 & 0.003 & 1.29 & 1.091 .52 & 0.003 \\
\hline & BMI & & $<0.001$ & & 0.003 & & & 0.004 \\
\hline & $<18.5$ & Ref & & Ref & & Ref & & \\
\hline & $18.5-24.9$ & 0.600 .490 .75 & $<0.001$ & 0.740 .590 .91 & 0.006 & 0.74 & 0.590 .92 & 0.007 \\
\hline & $\geq 25.0$ & 0.500 .370 .66 & $<0.001$ & 0.600 .450 .81 & 0.001 & 0.61 & 0.450 .82 & 0.001 \\
\hline & Medical insurance type & & 0.046 & & & & & \\
\hline & Self-paid & Ref & & & & & & \\
\hline & Rural-insurance & 0.710 .560 .91 & 0.006 & & & & & \\
\hline & Urban-insurance & 0.730 .570 .94 & 0.015 & & & & & \\
\hline & Others & 0.950 .352 .60 & 0.923 & & & & & \\
\hline & Occupation & & 0.872 & & & & & \\
\hline & No & Ref & & & & & & \\
\hline & Yes & 1.030 .741 .43 & 0.872 & & & & & \\
\hline & Income & & 0.218 & & & & & \\
\hline & Very low & Ref & & & & & & \\
\hline & Low & 0.860 .711 .04 & 0.121 & & & & & \\
\hline & General & 0.960 .761 .22 & 0.745 & & & & & \\
\hline & High & 0.660 .391 .12 & 0.124 & & & & & \\
\hline & Social status & & 0.426 & & & & & \\
\hline & Very low & Ref & & & & & & \\
\hline & Low & 0.990 .521 .87 & 0.978 & & & & & \\
\hline & General & 0.880 .471 .65 & 0.692 & & & & & \\
\hline & High & 0.730 .371 .46 & 0.375 & & & & & \\
\hline & Vert high & 0.910 .402 .11 & 0.832 & & & & & \\
\hline & Residential address & & 0.745 & & & & & \\
\hline & Village & Ref & & & & & & \\
\hline & City & 0.980 .841 .14 & 0.745 & & & & & \\
\hline & Marital status & & 0.515 & & & & & \\
\hline & No & Ref & & & & & & \\
\hline & Yes & 0.800 .421 .55 & 0.515 & & & & & \\
\hline & Procreation status & & 0.209 & & & & & \\
\hline & No & Ref & & & & & & \\
\hline & Yes & 0.680 .381 .24 & 0.209 & & & & & \\
\hline & $\begin{array}{l}\text { Smoking and drinking } \\
\text { consumption }\end{array}$ & & 0.312 & & & & & \\
\hline & No & Ref & & & & & & \\
\hline & Smoking & 0.880 .721 .06 & 0.167 & & & & & \\
\hline & Drinking & 1.260 .831 .90 & 0.273 & & & & & \\
\hline
\end{tabular}




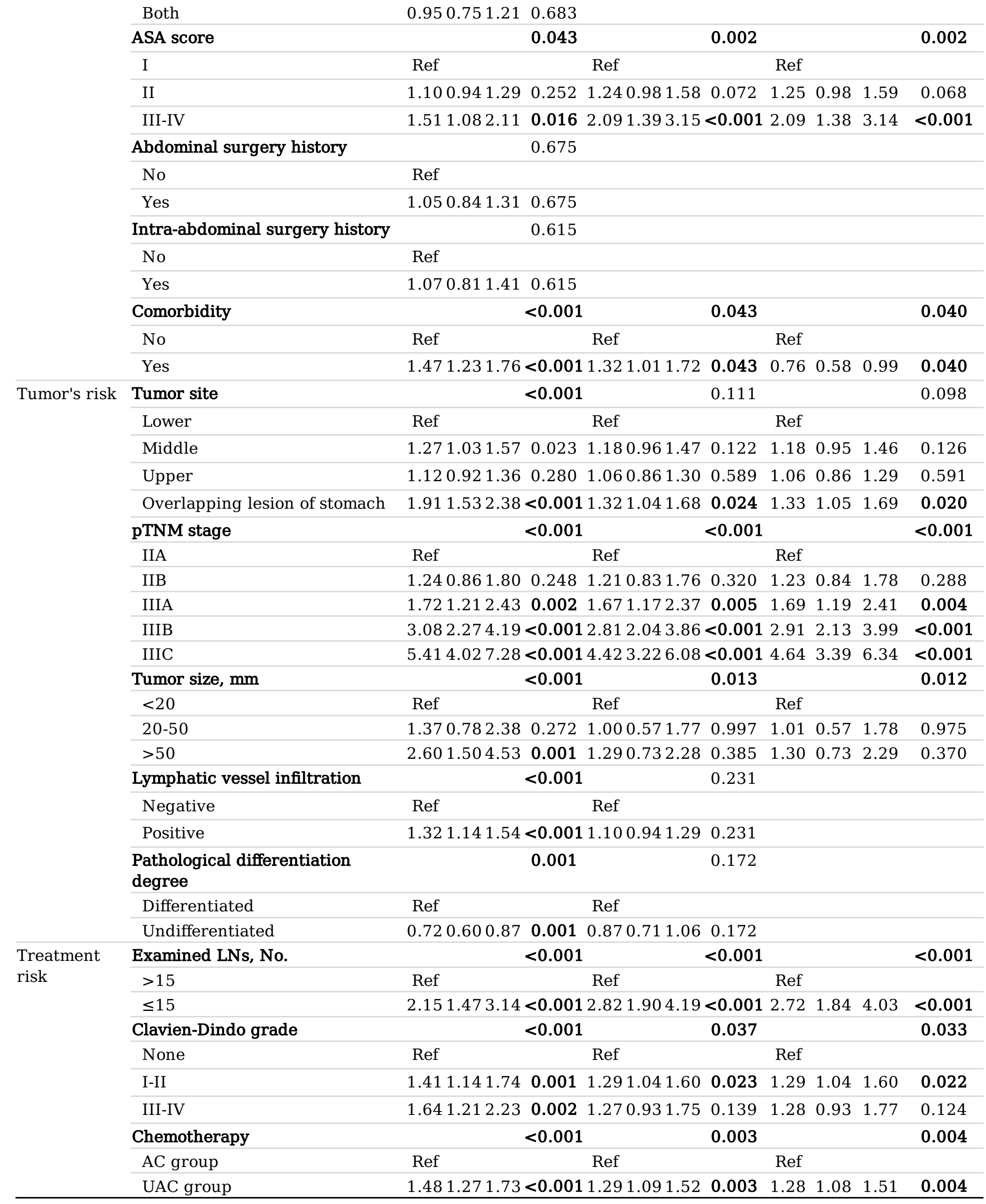


Table 3. Univariate and multivariate logistic models for the risks of unacceptable chemotherapy 


\begin{tabular}{|c|c|c|c|c|c|c|c|c|c|}
\hline \multicolumn{2}{|l|}{ Variable } & \multicolumn{2}{|c|}{ Univariate Model } & \multicolumn{2}{|c|}{$\begin{array}{c}\text { Full Multivariate } \\
\text { Model }\end{array}$} & \multicolumn{4}{|c|}{$\begin{array}{c}\text { Reduced Multivariate } \\
\text { Model }\end{array}$} \\
\hline & & OR $\quad 95 \% \mathrm{CI}$ & $\mathrm{P}$ & OR $95 \%$ CI & $\mathrm{P}$ & OR & & $5 \% \mathrm{CI}$ & $\mathrm{P}$ \\
\hline \multirow[t]{46}{*}{ Patients' risk } & Gender & & 0.030 & & 0.011 & & & & 0.015 \\
\hline & Female & Ref & & Ref & & Ref & & & \\
\hline & Male & 0.770 .610 .98 & 0.030 & 0.720 .550 .93 & 0.011 & 0.73 & 0.56 & $\begin{array}{ll}6 & 0.94\end{array}$ & 0.015 \\
\hline & Age,year & & $<0.001$ & & $<0.001$ & & & & $<0.001$ \\
\hline & $<65$ & Ref & & Ref & & Ref & & & \\
\hline & $\geq 65$ & 2.802 .253 .47 & $<0.001$ & 2.471 .923 .19 & $<0.001$ & 2.45 & 1.91 & 13.14 & $<0.001$ \\
\hline & BMI & & 0.470 & & & & & & \\
\hline & $<18.5$ & Ref & & & & & & & \\
\hline & $18.5-24.9$ & 0.830 .601 .14 & 0.246 & & & & & & \\
\hline & $\geq 25.0$ & 0.800 .531 .20 & 0.279 & & & & & & \\
\hline & Medical insurance type & & $<0.001$ & & $<0.001$ & & & & $<0.001$ \\
\hline & Self-paid & Ref & & Ref & & Ref & & & \\
\hline & Rural-insurance & 0.380 .270 .54 & $<0.001$ & 0.390 .270 .57 & $<0.001$ & 0.39 & 0.26 & $\begin{array}{ll}6 & 0.57\end{array}$ & $<0.001$ \\
\hline & Urban-insurance & 0.470 .330 .68 & $<0.001$ & 0.380 .250 .57 & $<0.001$ & 0.36 & 0.24 & 40.55 & $<0.001$ \\
\hline & Others & 0.420 .101 .72 & 0.226 & 0.180 .040 .93 & 0.040 & 0.19 & 0.04 & $4 \quad 0.92$ & 0.040 \\
\hline & Occupation & & 0.534 & & & & & & \\
\hline & No & Ref & & & & & & & \\
\hline & Yes & 1.170 .721 .90 & 0.534 & & & & & & \\
\hline & Income & & 0.004 & & 0.186 & & & & \\
\hline & Very low & Ref & & Ref & & & & & \\
\hline & Low & 0.640 .490 .83 & 0.001 & 1.400 .942 .08 & 0.094 & & & & \\
\hline & General & 0.730 .521 .01 & 0.060 & 1.170 .691 .98 & 0.563 & & & & \\
\hline & High & 0.430 .200 .91 & 0.028 & 0.630 .192 .09 & 0.447 & & & & \\
\hline & Social status & & $<0.001$ & & 0.001 & & & & 0.001 \\
\hline & Very low & Ref & & Ref & & Ref & & & \\
\hline & Low & 0.280 .100 .80 & 0.017 & 0.250 .080 .73 & 0.012 & 0.26 & 0.09 & 90.78 & 0.016 \\
\hline & General & 0.140 .050 .40 & $<0.001$ & 0.140 .050 .43 & 0.001 & 0.18 & 0.06 & $\begin{array}{ll}6 & 0.52\end{array}$ & 0.002 \\
\hline & High & 0.230 .080 .67 & 0.007 & 0.190 .060 .67 & 0.009 & 0.19 & 0.06 & $\begin{array}{ll}6 & 0.62\end{array}$ & 0.005 \\
\hline & Vert high & 0.120 .030 .47 & 0.002 & 0.140 .020 .84 & 0.032 & 0.08 & 0.02 & 20.36 & 0.001 \\
\hline & Residential address & & 0.011 & & 0.063 & & & & 0.072 \\
\hline & Village & Ref & & Ref & & Ref & & & \\
\hline & City & 1.321 .071 .63 & 0.011 & 1.340 .981 .82 & 0.063 & 1.31 & 0.98 & 81.76 & 0.072 \\
\hline & Marital status & & 0.544 & & & & & & \\
\hline & No & Ref & & & & & & & \\
\hline & Yes & 0.750 .301 .88 & 0.544 & & & & & & \\
\hline & Procreation status & & 0.799 & & & & & & \\
\hline & No & Ref & & & & & & & \\
\hline & Yes & 0.890 .372 .16 & 0.799 & & & & & & \\
\hline & $\begin{array}{l}\text { Smoking and drinking } \\
\text { consumption }\end{array}$ & & 0.212 & & & & & & \\
\hline & No & Ref & & & & & & & \\
\hline & Smoking & 0.840 .651 .09 & 0.198 & & & & & & \\
\hline & Drinking & 0.820 .441 .54 & 0.534 & & & & & & \\
\hline & Both & 0.720 .521 .02 & 0.062 & & & & & & \\
\hline & ASA score & & $<0.001$ & & 0.129 & & & & 0.047 \\
\hline & $\mathrm{I}$ & Ref & & Ref & & Ref & & & \\
\hline & II & 1.561 .251 .95 & $<0.001$ & 1.240 .881 .75 & 0.212 & 1.26 & 0.99 & 91.60 & 0.063 \\
\hline
\end{tabular}


III-IV

Abdominal surgery history

No

Yes

Intra-abdominal surgery history

No

Yes

Charlson score

0

$1-2$

3-5

Tumor's risk Tumor site

\begin{tabular}{l} 
Lower \\
Middle \\
\hline Upper \\
Overlapping lesion of stomach \\
\hline TNM stage
\end{tabular}

pTNM stage

IIA

IIB

IIIA

IIIB

IIIC

Tumor size, $\mathrm{mm}$

$<20$

20-50

$>50$

Lymphatic vessel infiltration

Negative

Positive

Pathological differentiation

degree

Differentiated

Undifferentiated

Treatment risk

\section{Examined LNs, No.}

$$
>15
$$$$
\leq 15
$$

Clavien-Dindo grade

None

I-II

III-IV
$2.461 .484 .09<0.0011 .961 .013 .81 \quad 0.047 \quad 1.741 .013 .02$ $<0.001$

0.002

0.047

0.003

Ref Ref Ref

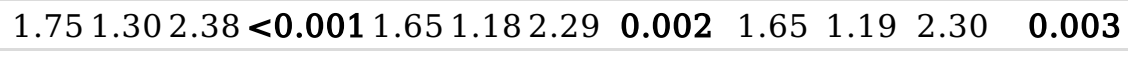
0.501

Ref

$1.150 .771 .70 \quad 0.501$

$<0.001$

Ref

\section{Ref}

$1.681 .332 .11<0.0010 .950 .651 .400 .798$

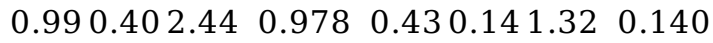

0.684

Ref

$0.890 .671 .18 \quad 0.415$

$1.050 .811 .36 \quad 0.731$

$1.070 .771 .49 \quad 0.688$

0.224

Ref

$0.860 .591 .24 \quad 0.413$

0.720 .491 .050 .084

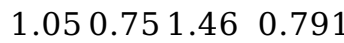

$0.990 .711 .37 \quad 0.929$

0.105

Ref

$0.900 .491 .66 \quad 0.739$

$1.140 .622 .10 \quad 0.680$

0.326

Ref

0.900 .731 .110 .326

$$
0.342
$$

Ref

$1.130 .881 .44 \quad 0.342$

0.629

Ref

1.170 .622 .210 .629

$<0.001$

Ref

$<0.001$

$<0.001$

Ref $\quad$ Ref

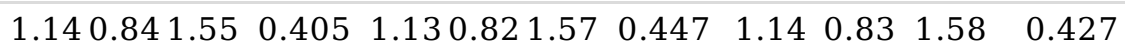
$3.992 .436 .53<0.0013 .832 .256 .53<0.0013 .732 .206 .33<0.001$

AC: Acceptable chemotherapy, UAC: Unacceptable delay or missing chemotherapy, LN: lymph node

\section{Figures}




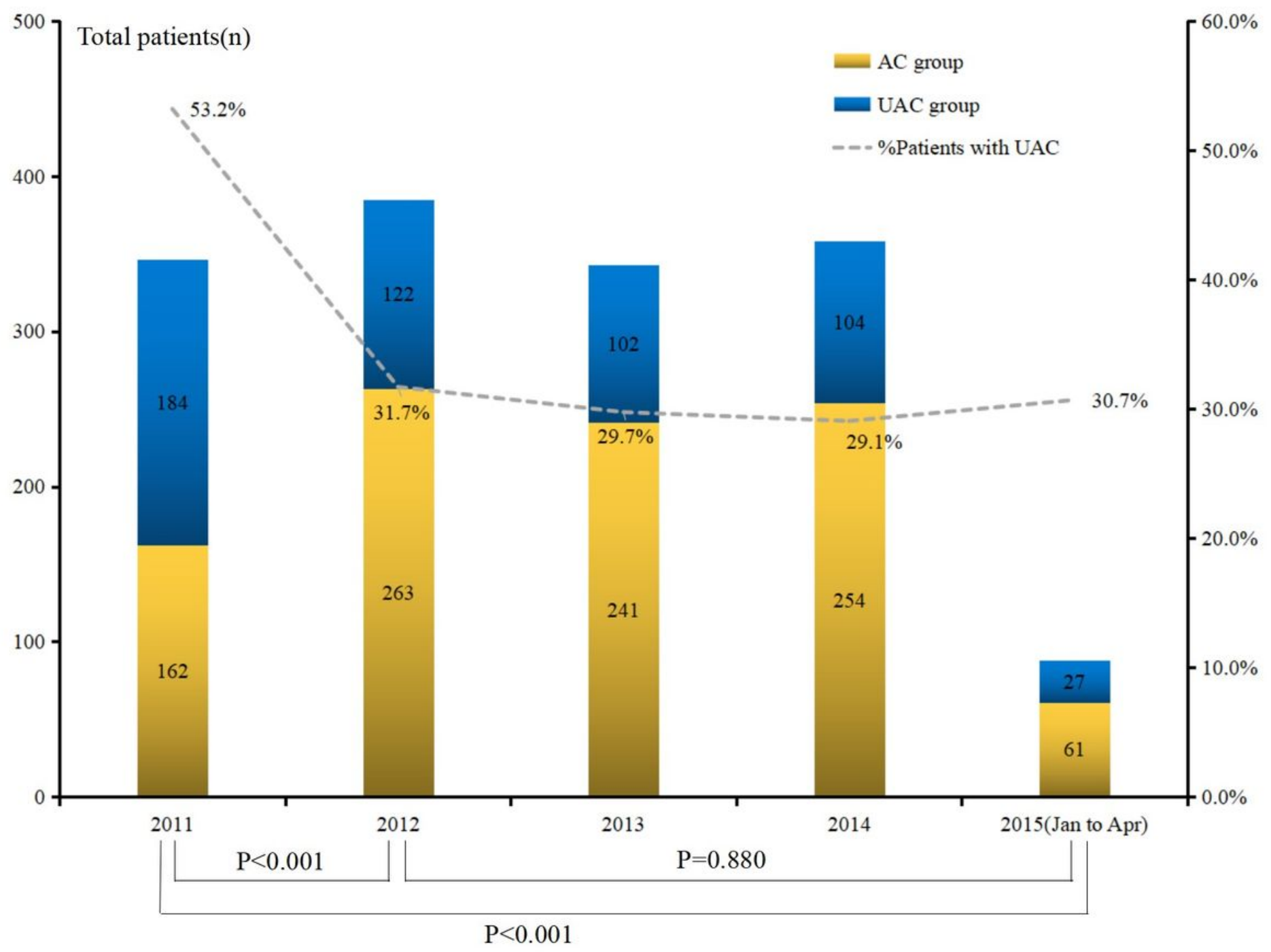

Figure 1

Fig. 1 The trend of unacceptable chemotherapy in pathological stage II/III stage gastric cancer patients between 2011 and April 2015 

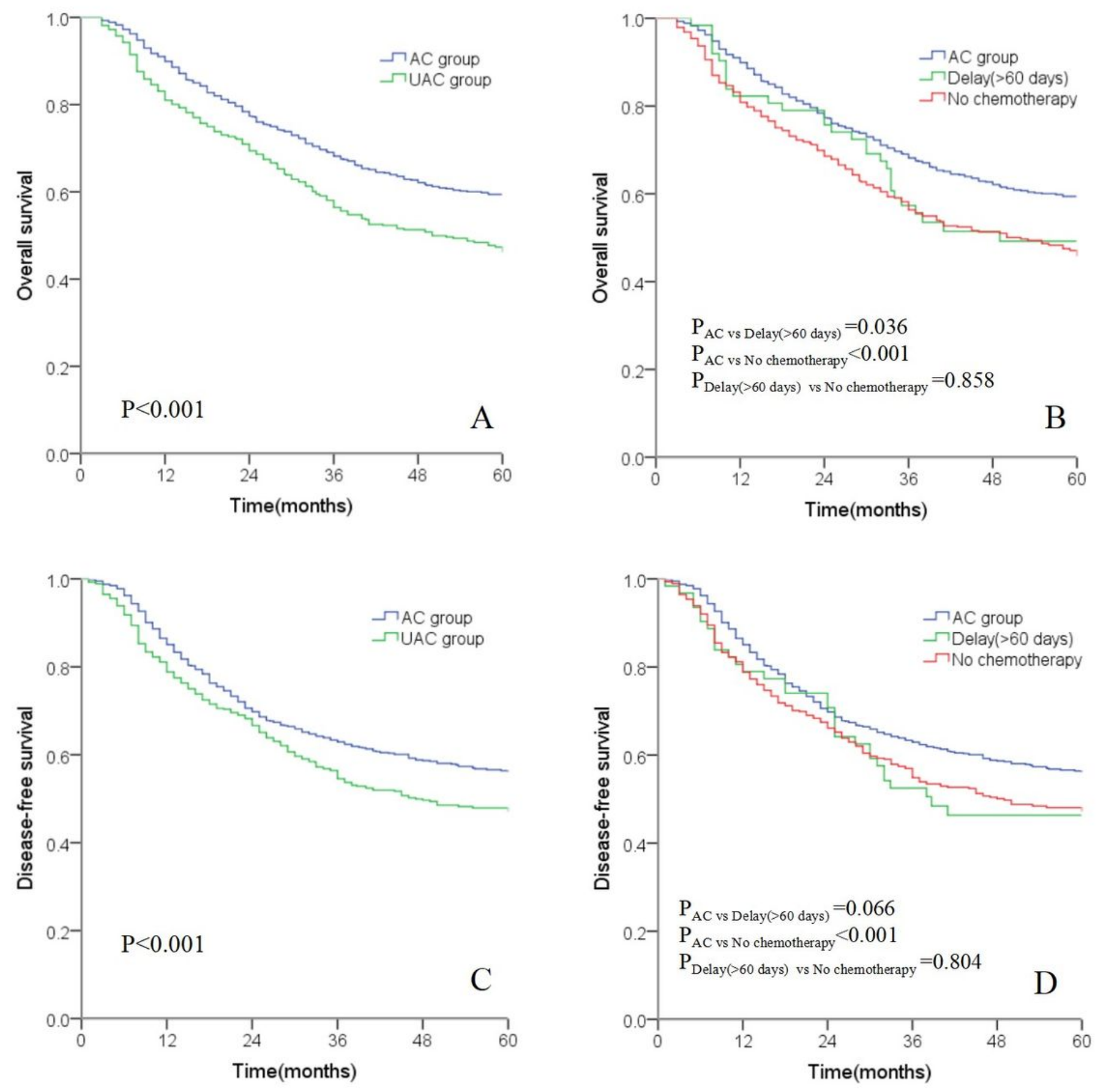

Figure 2

Fig. 2 Survival of patients in AC and UAC groups. A: The OS of AC group vs UAC group. B: the OS among AC group, Delay (>60 days) and No chemotherapy. C: the DFS of AC group vs UAC group. D: the DFS among AC group, Delay (>60 days) and No chemotherapy. 


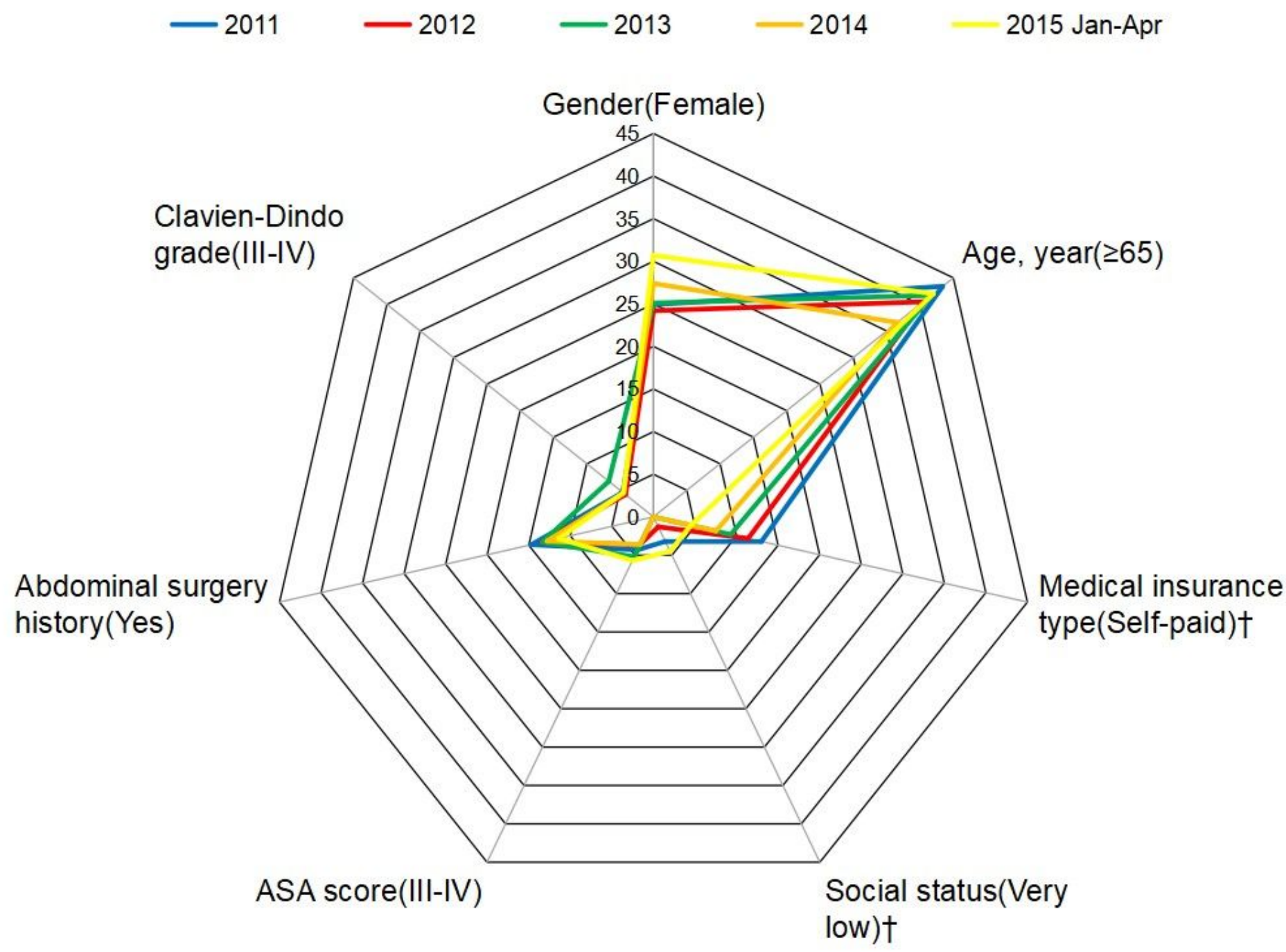

Figure 3

Fig. 3 Analysis of the risk factors of unacceptable chemotherapy from 2011 to April 2015, † P value $<0.05$.

\section{Supplementary Files}

This is a list of supplementary files associated with this preprint. Click to download.

- SupplementaryTable.doc 